\title{
A POTÊNCIA DO PROCESSO GRUPAL ${ }^{1}$
}

\author{
THE POWER OF GROUP PROCESS
}

EL PODER DEL PROCESO GRUPAL

Marcos Vieira-Silva*

\begin{abstract}
RESUMO
Partindo de um programa de pesquisa-intervenção psicossocial, este trabalho apresenta questionamentos e consideraçóes sobre grupos comunitários e institucionais, objetos de ações de pesquisa e extensão do Laboratório de Pesquisa e Intervenção Psicossocial (Lapip) da Universidade Federal de São João del-Rei (UFSJ). As perspectivas de análises partem de autores que trabalham com a concepção dialética sobre grupos humanos e o processo grupal, como Ignácio Martín-Baró e Sílvia Lane, e com as concepções de grupo operativo, de Enrique Pichón-Rivière, e oficinas de grupo, de Lúcia Afonso. Nos grupos investigados/atendidos, encontramos fenômenos grupais produtores de identidade e ativadores de consciência, além de uma insistência em se manterem como grupos, resistindo ao individualismo e ao isolamento social. Processos de coesão e identidades coletivas são produzidos em associação com mecanismos de solidariedade e afetividade. Presenciamos relações de poder mais igualitárias, implicando menos submissão e mais disposição para o trabalho educativo, com mais possibilidades de produção coletiva de conhecimentos.
\end{abstract}

Palavras-chave: Grupo. Processo grupal. Afetividade. Identidade grupal. Inclusão psicossocial.

\begin{abstract}
Based on a psychosocial intervention research program, this work presents questions and considerations on community and institutional groups while subjects of a research and extension of the Laboratory of Research and Psychosocial Intervention of the Federal University of São João del-Rei (UFSJ). As object of analysis they come from authors who work with the dialectic conception on human groups and the group processing, such as Ignácio Martín-Baró and Sílvia Lane, and the concepts of operating group, by Enrique Pichón-Rivière, and group workshops, by Lúcia Afonso. In the investigated/assisted groups, we find group phenomena which are producers of identity and consciousness activators, beside insisting in being groups,
\end{abstract}

Texto dedicado à Prof. a Sílvia Lane (in memoriam) grande mestra e incansável praticante da Psicologia social crítica.

" Professor associado IV, aposentado, da Universidade Federal de São João del-Rei (UFSJ), professor voluntário do quadro permanente do Programa de Pós-Graduação em Psicologia da UFSJ, coordenador do GT Psicologia Comunitária da Anpepp (Associação Nacional de Pesquisa e Pós-Graduação em Psicologia), sócio-fundador da Abrapso (Associação Brasileira de Psicologia Social). 
struggling against individualism and social isolation. Cohesion processes and collective identities are produced linked to mechanism of solidarity and affectivity. We have witnessed more egalitarian power relations, involving less submission and more disposition for the educational work, with more possibilities of collective production of knowledge.

Keywords: Group. Group process. Affectivity, Group identity. Psychosocial Inclusion.

\section{RESUMEN}

A partir de un programa de investigación de intervención psicosocial, el trabajo presenta preguntas y consideraciones sobre grupos comunitarios e institucionales, objeto de investigación y acciones de extensión de Lapip (Laboratorio de Investigación e Intervención Psicosocial) de UFSJ. Las perspectivas de análisis provienen de autores que trabajan con la concepción dialéctica de los grupos humanos y el proceso grupal, como Ignácio Martín-Baró y Sílvia Lane, y con las concepciones de Enrique PichónRivière del grupo operativo, y los talleres grupales de Lúcia Alfonso. En los grupos investigados/asistidos, encontramos fenómenos grupales que producen identidad y activadores de conciencia, así como una insistencia en permanecer como grupos, resistiendo al individualismo y al aislamiento social. Los procesos de cohesión y de identidades colectivas se producen en asociación a mecanismos de solidaridad y afecto. Fuimos testigos de relaciones de poder más igualitarias, lo que implica menos sumisión y más disposición para el trabajo educativo, con más posibilidades de producción de conocimiento colectivo.

Palabras clave: Grupo. Proceso grupal. Afectividad. Identidad grupal. Inclusión Psicosocial.

\section{DE ONDE VENHO E A PARTIR DE QUE LUGARES/ PERSPECTIVAS EU FALO}

M inha convivência com os grupos começa com a realização do primário, cursado no Grupo Escolar Olegário Maciel, e do ginasial, cursado no Colégio Estadual de Minas Gerais, ambas escolas públicas de Minas Gerais, localizadas em Belo Horizonte. Foram períodos marcados por duas características: uma, a falta de clareza sobre muitas coisas da política e da vida cotidiana, mas uma grande e silenciosa cumplicidade com colegas e primos; a outra, a vergonha de cantar o Hino Nacional na entrada obrigatória dos alunos em forma, no pátio da escola, durante o curso primário e no decorrer das aulas de música, no ginásio, período vivido na década de 1960, durante a ditadura civil-militar. Somente fui perder essa vergonha e voltar a cantar o Hino durante 
a campanha das Diretas Já, em 1979. É claro que só tomei consciência dessa minha história pessoal de envolvimento com grupos durante a formação em Psicologia e o envolvimento com o movimento estudantil (ME).

Em 1974, após aprovação em um concurso vestibular difícil, comecei a cursar Psicologia na Faculdade de Filosofia e Ciências Humanas (Fafich) da Universidade Federal de Minas Gerais (UFMG). Já durante as calouradas, comecei a conviver com os colegas e com o ME, convivência intensa que foi se ampliando e durou cinco anos, os cinco anos de duração da graduação em Psicologia.

Foram cinco anos de grupos, reuniões, assembleias, comissões paritárias, atos públicos e corridas da polícia pelas ruas de Belo Horizonte. O Centro de Estudos de Psicologia (CEP), o Diretório Acadêmico da Fafich (DA Fafich) e o Setor de Psicologia Social, que congregava os professores que atuavam nessa área, foram minha segunda casa. De acordo com minha mãe, a maior parte do tempo, foram minha primeira casa. A convivência coletiva com a democracia, com as assembleias, a leitura daquilo que era proibido ou daquilo que não era "conveniente" ser estudado em salas de aula era possível pelos textos mimeografados pelo DA e pelo Centro de Estudos. A discussão coletiva dos currículos, conteúdos e planos de ensino de várias disciplinas era prática corrente. Durante o primeiro período do curso, fui estimulado pelos colegas a participar de uma comissão paritária, formada por alunos e professores, que estava trabalhando na construção de um novo currículo para o Curso de Psicologia. Tudo era decidido pelo coletivo, e todas as informaçôes circulavam entre todos. Com pouco tempo de trabalho, eu conhecia todo o currículo do curso e as propostas de estágios, embora estivesse ainda cursando o segundo período.

Fiz de tudo, de ME a teatro, passando pelo futebol e pelo vôlei, e cursei Psicologia e várias disciplinas isoladas de Filosofia, além de cursos de extensão em Filosofia e Cultura. Fui monitor de vários professores do Setor de Psicologia Social que se tornaram referências importantes na Psicologia social brasileira (Marília Novais da Mata Machado, Maria Lúcia Miranda Afonso, Cornelis Joanes Van Stralen, Regina Helena de Freitas Campos, José Renato Amaral, José Newton Garcia de Araújo). Ao fim do curso, momento de escolher os estágios curriculares para fechar a formação, escolhi um estágio em Psicologia comunitária, na área de saúde, em Montes Claros. O professor Cornelis Van Stralen era o supervisor. O segundo estágio foi realizado em Saúde Mental, no Instituto Raul Soares, hospital psiquiátrico público ligado à Fundação Hospitalar do Estado de Minas Gerais (Fhemig), onde funcionava a Residência em Psiquiatria. Foi o começo de minha formação em pesquisa, da atuação na extensão universitária, da formação em práticas grupais e da militância na Luta Antimanicomial, temáticas/questôes que nunca mais abandonei. 
Em 1979, seis meses após a formatura, comecei a trabalhar com docência na Universidade Católica de Minas Gerais (UCMG), no Curso de Serviço Social e, depois de um ano e meio, no Curso de Psicologia. Primeira disciplina no Serviço Social: Psicologia Social dos Grupos. Logo depois, Psicologia Social e Saúde Mental. Na época, cursava uma especialização em Dinâmica de Grupos-Grupos Operativos e já participava da Diretoria da Sociedade Mineira de Psicologia. Organizamos a Associação Profissional dos Psicólogos de Minas Gerais, embrião do futuro Sindicato dos Psicólogos de Minas Gerais e a primeira chapa de oposição para o Conselho Regional de Psicologia (4a Região - Minas Gerais e Espírito Santo). Participei ativamente do III Congresso Mineiro de Psiquiatria, que, contando com a presença marcante de Franco Basaglia, desencadeou a Reforma da Assistência à Saúde Mental em Minas Gerais. "Em nome da razão", documentário de Helvécio Ratton, cineasta e psicólogo, e "Nos porões da loucura", série de reportagens e livro de Hiran Firmino, jornalista do jornal Estado de Minas, tornaram-se ícones da Luta Antimanicomial mineira. Em um seminário realizado pelo Conselho Regional de Psicologia na Faculdade de Medicina da UFMG, conheci a Prof. a Sílvia Lane. Pedi sugestôes de referências para utilizá-las com meus alunos e comecei a adotar seus textos em minhas disciplinas de Psicologia Social.

Na UCMG, a partir do Curso de Serviço Social, fui trabalhar com a extensão no Vale do Jequitinhonha, Campus Avançado da Universidade, no Norte do Estado de Minas e uma das regiôes mais pobres do País, do ponto vista socioeconômico, mas também mais rica em termos de cultura e produção de artesanato, e na Vila Barraginha, chamada de campus Aproximado, um aglomerado localizado na periferia da cidade de Belo Horizonte, região conhecida como Cidade Industrial. As temáticas mais presentes nesses trabalhos foram "Grupos e promoção de cultura", "Grupos e promoção de saúde", "Artesanato" e "Música”. Tornei-me supervisor de projetos de extensão que contavam com a participação de alunos dos cursos de Psicologia, Serviço Social e Enfermagem.

Na década de 1980, cursei o Mestrado em Educação, na Faculdade de Educação (FAE) da UFMG. Tive a felicidade e o privilégio de cursar uma disciplina eletiva, com Paulo Freire. Até hoje, sinto-me profundamente contemplado em minha maneira de ser professor. Reforçam-se para mim a potência e a riqueza dos grupos como espaços e possibilidades de participação social e envolvimento coletivo com arte e cultura, saúde e desenvolvimento social.

Vale lembrar a presença forte da Associação Brasileira de Psicologia Social (Abrapso), fundada durante a Reunião da Sociedade Brasileira para o Progresso da Ciência, em julho de 1980, na Universidade do Estado do Rio de Janeiro (UERJ), durante todo esse percurso e as parcerias institucionais que ela nos 
proporcionou. Sou um dos dois psicólogos mineiros que são sócios-fundadores da Abrapso.

Em junho de 1989, a ida para a Fundação de Ensino Superior de São João del-Rei (Funrei), instituição federal de ensino superior na cidade de São João del-Rei. Fui trabalhar no Curso de Psicologia, em que a Psicologia Social é forte, com muitas práticas de disciplinas e estágios. No segundo semestre, consegui aprovação em concurso público e passei a pertencer ao quadro permanente da instituição. Trabalhar com ensino, pesquisa e extensão como atividades obrigatórias e permanentemente remuneradas era tudo o que eu queria.

Em 1995, consegui liberação institucional para cursar o Doutorado na PUCSP, com bolsa da CAPES. Só podia ser com Sílvia Lane como orientadora, com quem eu já convivia por cerca de 15 anos, em razão da Abrapso. Já havíamos falado muito sobre a possibilidade de cursar o Doutorado, mas era muito difícil ir sem bolsa, o que foi o diferencial naquele ano. Temática do anteprojeto: Grupos. Foi um período de intensa convivência e de longas conversas com ela. Seu encantamento, incentivos e respeito para com os trabalhos dos orientandos eram um grande apoio e incentivo. Já ao fim do curso, durante o exame de qualificação do doutorado, a Prof.a Bader me apresentou uma questão: "O que o doutorado significou para você, como impactou sua formação e seu trabalho como professor?". Eu respondi que era um professor muito melhor do que antes do doutorado. Eu me sentia muito mais motivado e mais envolvido com a vida acadêmica.

Dezembro de 2000, a volta para São João del-Rei com o diploma de doutor. Diploma que, de certa forma, representava a "carta de alforria" do "pesquisador implicado". Podia, agora, pesquisar o que quisesse em minha área de atuação e pleitear financiamentos para pesquisas, o que foi um grande diferencial.

Voltando um pouco no tempo, em junho de 2000, fundamos (um grupo de professores do Departamento de Psicologia da UFSJ) o Laboratório de Pesquisa e Intervenção Psicossocial (Lapip), uma produção coletiva, característica que sempre nos orgulhou, de professores das áreas de Psicologia Social, Psicologia Escolar e da Educação, Psicologia Organizacional e do Trabalho, e Psicologia Clínica. A principal característica do Lapip é a articulação entre pesquisa, extensão e ensino, a partir de projetos desenvolvidos pelos professores/pesquisadores e alunos bolsistas de iniciação científica, bolsistas de extensão, mestrandos e estagiários voluntários. O Laboratório conta também com uma sala de atividades físicas, uma lan house, uma brinquedoteca e o Centro de Documentação e Pesquisa em História da Psicologia (CDPHP). Nossa origem remota é o Laboratório de Psicologia Educacional e Experimental, criado na década de 1950, antes 
ainda da criação do próprio Curso de Psicologia, na Faculdade Dom Bosco de Filosofia, Ciências e Letras, criada pelos padres salesianos, origem da Funrei, hoje Universidade Federal de São João del-Rei (UFSJ).

Como eu dizia, o retorno à Funrei, que alcançou a condição de universidade em 2002, tornando-se UFSJ, com o doutorado realizado, proporcionou-me um intenso envolvimento com a pesquisa, a extensão e a gestão. Já havia passado pela experiência de ser coordenador do Curso de Psicologia antes do afastamento para cursar o doutorado. A partir do retorno, fui chefe de departamento, presidente da Fundação de Apoio à UFSJ, pró-reitor de Extensão e Assuntos Comunitários e membro de comissóes de assessoramento da Fapemig. Além disso, fui coordenador do Lapip por cerca de 15 anos. As pesquisas com os grupos das corporações musicais de São João del-Rei e região e dos idosos institucionalizados me proporcionaram uma bolsa de produtividade em pesquisa do CNPq e uma bolsa de pesquisador mineiro da Fapemig, financiamentos que foram muito importantes para a solidificação das minhas atividades de pesquisa e extensão. Fiz parte da comissão que trabalhou com a elaboração da proposta para criação do Programa de Mestrado em Psicologia da UFSJ, aprovada em 2008, e participo, até hoje, do corpo docente do Programa de Pós-Graduação em Psicologia (PPGPSI) da UFSJ, que implantou o doutorado em 2019. Desenvolvi, por vários anos, projetos de extensão e pesquisa com o Grupo de Inculturação Afrodescendentes Raízes da Terra, com o qual trabalhei durante minha pesquisa de doutoramento. Fiz também um estágio pós-doutoral na Faculdade de Educação da UFMG, com a temática da Inclusão Social e Educação Comunitária.

O Programa de Pesquisa "Processos grupais e articulações identitárias: possíveis parcerias e interações com políticas públicas de saúde e inclusão social - Fase 2 - Consolidando investigações e práticas de atenção psicossocial”, que vem sendo desenvolvido por mim junto ao Lapip, é um programa de pesquisa de intervenção psicossocial que investiga articulações teóricas e práticas entre categorias temáticas da Psicologia social. Compreende ações de pesquisa, extensão e ensino, desenvolvidas com grupos comunitários e institucionais em São João del-Rei e região, em Minas Gerais. Tem, como objetivo geral a investigação e o atendimento de demandas de vários grupos, entre eles a Associação dos Portadores de Diabetes de São João del-Rei, corporações musicais de São João del-Rei e da Região dos Campos das Vertentes, grupos de idosos institucionalizados e comunitários, grupos de pessoas com deficiência, grupos de diabéticos, além de outros grupos e associações comunitárias da cidade e região que são objeto de ações desenvolvidas pelo Lapip, em parcerias ou interações com órgãos públicos e movimentos sociais, com base em políticas públicas federais, estaduais ou municipais de saúde, educação, inclusão social e desenvolvimento social. 
Para estabelecer uma linha de ação que atravessa tudo isso e proporciona várias amarras, talvez fosse importante voltarmos ao tema dos grupos e do processo grupal. Lane (1984) considera que o grupo é

Condição necessária para conhecer as determinaçôes sociais que agem sobre o indivíduo, bem como a sua ação como sujeito histórico, partindo do pressuposto que toda ação transformadora da sociedade só pode ocorrer quando indivíduos se agrupam (p. 78).

É também Lane (1984) quem propõe, a partir de investigações com alunos da Pós-Graduação em Psicologia Social da PUC-SP, algumas premissas para que se possa conhecer grupos e processo grupal:

1) o significado da existência e da ação grupal só pode ser encontrado dentro de uma perspectiva histórica que considere a sua inserção na sociedade, com suas determinações econômicas, institucionais e ideológicas;

2) o próprio grupo só poderá ser conhecido enquanto um processo histórico e, neste sentido, talvez fosse mais correto falarmos em processo grupal, em vez de grupo (Lane, 1984, p. 81).

Pensando ainda sobre processo grupal e partindo de Lane e Pichón-Rivière, venho trabalhando e considerando processo grupal como as maneiras/estratégias pelas quais o grupo vai produzindo, criticamente, o seu próprio modo de ser grupo, o processo de se organizar para desenvolver o seu fazer, realizar suas tarefas, sejam as que lhe foram propostas ou as que ele se propóe por vontade própria, em razão de suas atividades cotidianas. Vale lembrar que "grupo é gerúndio", ou seja, ele não está pronto, ele está sempre se fazendo, sempre em processo de produção de si mesmo e de seus modos de ser grupo.

Pensar o grupo como processo grupal permite captar seu movimento permanente, seja na realização de suas tarefas, seja na construção de sua identidade, seja nas suas "idas e vindas" em torno da produção de seus projetos coletivos e na dialética permanente do seu transitar entre esses projetos e os interesses individuais. O grupo é, com certeza, o lugar da multiplicidade e não da homogeneidade [. . .]. Seu desafio é a construção de um projeto coletivo a partir das heterogeneidades de seus membros. Partindo dessas premissas não faz sentido uma definição fechada, acabada do grupo. Ele está sempre por fazer-se, está a todo momento em construção, em processo, avaliando e produzindo sua história, a partir da história de cada um e de suas implicaçóes na história coletiva (Vieira-Silva, 2000, p. 16).

Nossas investigações têm se perguntado e problematizado questôes sobre: 
a) a produção das formações identitárias nas corporações musicais (bandas e orquestras) de São João del-Rei e região, e suas articulações com o desenvolvimento da formação musical, tanto do ponto de vista técnico quanto do ponto de vista da construção de uma relação de afetividade no desenvolvimento do processo do fazer musical;

b) como o fazer musical promove o reconhecimento e a produção da identidade cultural em São João del-Rei e na região dos Campos das Vertentes? Como a convivência com a cultura interfere/atua/provoca a produção da identidade de músico na região?;

c) como as implicaçōes psicossociais do diabetes mellitus, focando principalmente as relações entre identidade individual, identidade grupal e participação social, interferem/problematizam/produzem a participação e o envolvimento afetivo-emocional em ações de saúde por parte dos diabéticos atendidos pelas várias unidades de saúde e pela Associação dos Portadores de Diabetes de São João del-Rei?;

d) que relações podem ser/têm sido estabelecidas entre identidade individual, identidade grupal e cultura, pensando nas várias corporações musicais (bandas e orquestras) que atuam na Região dos Campos das Vertentes e, especificamente, que atuam em São João del-Rei?;

e) que relações podem ser/têm sido estabelecidas entre ludicidade, afetividade, identidade e memória no trabalho de atenção psicossocial a idosos institucionalizados em São João del-Rei e região? As instituições de longa permanência para idosos (ILPI) podem/querem trabalhar na perspectiva de centros de convivência? Nossas atuações com os idosos nas instituições da região nos mostraram que, com todas as limitaçôes que a institucionalização produz, ainda existe um nós entre os idosos em várias situações/ atividades. Uma política pública municipal de atenção ao idoso pode surgir da interação das ações das ILPI com as práticas de extensão universitária desenvolvidas pela UFSJ e pelo IF Sudeste (Instituto Federal de Ciência e Tecnologia)?;

f) como as categorias temáticas Afetividade Grupal, Identidade Grupal, Afrodescendência, Memória Coletiva, Participação Social, Inclusão Psicossocial, Grupo e Processo Grupal podem ser trabalhadas, na perspectiva da Psicologia social comunitária, na articulação e parcerias das práticas de extensão universitária com as políticas públicas municipais de atenção psicossocial; 
g) com as condições sociais vivenciadas e na conjuntura política atual, como os grupos comunitários atendidos pelo Sistema Único de Assistência Social (SUAS) podem/conseguem articular suas demandas com a realidade das açôes propostas/realizadas pelos dispositivos de Assistência Social?;

h) como as ações/fundamentações propostas pela Psicologia social comunitária estão sendo encaminhadas pelos profissionais que "fazem a atenção psicossocial" no Município e na região? O questionamento vale para os Centros de Atenção Psicossocial (CAPS), Centro de Testagem e Aconselhamento (CTA) e outros dispositivos que trabalham com a política de álcool e outras drogas, na perspectiva da redução de danos, bem como para instituiçôes semelhantes.

As questôes colocadas acima são propostas em conjunto com a investigação e com os estudos de categorias temáticas da Psicologia social crítica, comentados a seguir.

\section{IDENTIDADE GRUPAL}

Se não podemos dizer que o comportamento de um grupo é equivalente à soma dos comportamentos dos indivíduos que o compóem, isso também vale para a identidade grupal. Ela é diferente da "soma" das identidades dos membros, é uma produção coletiva, que tem muito mais a ver com a trajetória do grupo em torno de suas atividades, objetivos, história coletiva do que com uma "nomeação" que tenha sido proposta para o grupo. A identidade grupal vai sendo construída paralelamente ao desenvolvimento de um sentido e de um sentimento de "pertença" (Vieira-Silva, 2000).

De acordo com Martín-Baró (1989), para que haja uma identidade grupal, não significa que todos os membros tenham o mesmo traço comum. "O que a identidade grupal requer é que exista uma totalidade, uma unidade de conjunto, e que essa totalidade tenha uma peculiaridade que permita diferenciá-la de outras totalidades". Para o autor, três aspectos configuram basicamente a identidade de um grupo: sua formalização organizativa, suas relações com outros grupos e a consciência de seus membros acerca da sua condição de ser grupo. Para nós, decorrem daí algumas perguntas de pesquisa:

a) Como problematizar as configurações identitárias que são produzidas em contextos de vulnerabilidade social? 
b) Nesses contextos, podem surgir produções identitárias coletivas?

c) Como elas podem ser objeto de trabalho dos profissionais de Psicologia?

d) Que perspectivas de conscientização e transformação social podem surgir nesses contextos?

\section{AFETIVIDADE}

A unidade afetiva de um grupo não é uma unidade de fusão que suprime as experiências individuais, mas é uma unidade de relação com os outros, sentida coletivamente (Pagès, 1976).

Vínculos e afetividade, para Pichón-Rivière (1988). O autor defende que os vínculos que são estabelecidos entre os participantes de um determinado grupo são fundamentais para o desenvolvimento de processo de afetividade. Em algumas situações/atividades do "Programa Doce Vida", encontramos o humor como a estratégia adotada para lidar com a afetividade/implicaçôes afetivoemocionais da diabetes.

\section{IDENTIDADE E AFETIVIDADE}

No dizer de Agnes Heller (1985), os sentimentos nos envolvem com as situações. Nos grupos, os sentimentos e as emoções permeiam, direcionam ou redirecionam as relações pessoais e as reaçôes que manifestamos frente a determinadas situaçôes com as quais estamos envolvidos (Vieira-Silva, 2000, p. 23).

Como trabalhar a afetividade e suas implicações cotidianas nas ações/vivências cotidianas dos grupos sociais com populaçôes que enfrentam cotidianamente a violência e a miséria, tanto do ponto de vista social quanto econômico e cultural? Pagès pode ser considerado como um dos autores que mais trabalharam a afetividade nos grupos. Para ele,

A afetividade está presente de forma permanente nos grupos. Existem fenômenos afetivos que lhes são subjacentes, no desenvolvimento de suas atividades. Uma reunião de trabalho que não progride, embora os participantes disponham das informaçóes necessárias para tratar do problema. Nenhum deles é exageradamente neurótico. Não parece existirem conflitos insolúveis entre eles, mas cada um guarda informaçôes necessárias aos demais. Argumentos colocados suscitam argumentos opostos. A discussão se amarra no formalismo. Tudo se passa como se temores não formulados paralisassem os participantes. Temores de ser prejudicado ou explorado, de ter o grupo unido contra si, de ser excluído, de ser ridículo, de mostrar fraqueza da qual outros se aproveitarão (Vieira-Silva, 2000, p. 22). 
Aqui, novamente é importante se lembrar dos grupos de diabéticos na Associação dos Portadores de Diabetes de São João del-Rei (APD-SJDR), construindo relaçóes afetivas de cuidado, solidariedade e pertença a cada momento das reuniões e reflexões desenvolvidas na Associação.

Um grupo que consegue reconhecer a dimensão afetiva em suas relações consegue se estruturar melhor para exercer seu poder enquanto grupo frente às instituiçōes sociais. Quando os afetos, as emoções são vistos como parte integrante da identidade coletiva, é mais provável que o grupo consiga operar com maior pertinência nas suas relaçôes cotidianas e trabalhar seus conflitos (Vieira-Silva, 2000, p. 25).

É possível estabelecer princípios éticos para nosso trabalho em parceria com as políticas públicas do SUS e SUAS nesses contextos?

Trabalhamos com a concepção de extensão universitária, proposta pelo Fórum Nacional de Pró-Reitores de Extensão das Universidades Públicas Brasileiras, para quem a articulação com a pesquisa, ou pelo menos com a investigação, deve ser parte de uma busca permanente das ações cotidianas de extensão. Lembrando que a produção de conhecimentos se faz de forma dialógica, consideramos que a extensão acaba sendo um lugar privilegiado para tal produção, por ser um lugar/ espaço de diálogo e produção de conhecimentos entre o saber acadêmico e o popular.

Acreditamos que é importante destacar aqui alguns princípios, fundamentos e metodologias de ação que utilizamos. Lane (1996) defende que

O psicólogo na comunidade trabalha fundamentalmente com a linguagem e representaçōes, com relaçōes grupais - vínculo essencial entre o indivíduo e a sociedade - e com as emoçôes e afetos próprios da subjetividade, para exercer sua ação a nível de consciência, da atividade e da intensidade dos indivíduos que irão, algum dia, viver em verdadeira comunidade ( $\mathrm{p}$. $31)$.

Adotamos, como metodologia de ação, a pesquisa-intervenção psicossocial, que se pensa como um trabalho de produção de conhecimento sobre grupos, organizações, instituições, comunidades e movimentos sociais, fundado nas reflexôes teóricas e descobertas da Psicologia social e da Psicossociologia, e, simultaneamente, um conjunto de práticas clínicas de consulta voltadas para o tratamento desses diferentes conjuntos sociais e meios abertos.

A noção de pesquisa-intervenção psicossocial implica uma opção metodológica e uma ampliação do escopo de clínica, ultrapassando a ideia de "ao pé do leito", contida na etimologia da palavra. Ela surgiu e se consolidou nas Ciências Humanas e Sociais como uma metodologia especial, ao longo do século XX. 
Estamos trabalhando com perspectivas de intervenção psicossocial, atenção psicossocial e Psicologia comunitária que estabelecem relações de colaboração entre pesquisadores e pesquisados; os pesquisadores escutam os sujeitos participantes do conjunto social; pesquisadores e sujeitos sociais analisam, interpretam, refletem juntos, gravam, filmam, registram; pesquisadores fazem a devolução do que viram, ouviram, registraram. E então: "Juntos, pesquisadoresconsultores e pesquisados-clientes buscam solucionar problemas de ação e de mudança social. Com os clientes e/ou isoladamente, os pesquisadores procedem à elaboração teórica” (Machado, 2004, p. 15).

Tudo isso nos apresenta questionamentos e provocações permanentemente. No caso do trabalho com idosos institucionalizados, a ludicidade e a memória se unem à identidade e afetividade como categorias de investigação e intervenção. Jogos e brincadeiras de resgate de memórias individuais e coletivas são utilizados como disparadores e dispositivos de análise. Nosso desafio/provocação para as ILPI do Município e da região é a transformação de seu cotidiano na perspectiva de funcionarem como centros de convivência para idosos e entre idosos, e a população institucionalizada da região, ou, até mesmo, a criação de um centros de convivência para os municípios.

No caso da APD-SJDR, duas metas são objetos de nossas ações, investigações e reflexôes:

a) Possibilitar a busca de melhor qualidade de vida para os portadores de diabetes e seus familiares, trabalhando os fenômenos grupais, de forma a conduzi-los à reflexão e elaboração cotidiana das implicações afetivoemocionais da doença.

b) Estimular o desenvolvimento do processo grupal da APD, favorecendo a rede de comunicação, o fortalecimento dos vínculos, a afetividade grupal e a construção da identidade, tanto individual quanto coletiva, de diabéticos, buscando proporcionar, cotidianamente, maior adesão ao tratamento.

Consideramos que o "Doce Vida" tem desenvolvido metodologias que permitem/provocam a produção da identidade individual e coletiva de associado e portador de diabetes, mas nem tudo são flores. Existem dificuldades, tanto nos grupos atendidos na própria associação quanto nos atendidos pelas unidades de saúde do Município. Além disso, as políticas de atenção desenvolvidas pelos serviços de saúde funcionam com muita precariedade e pouco investimento financeiro. 
Por outro lado, o grupo da APD-SJDR parece demonstrar, em muitas de suas ações cotidianas, uma falta de envolvimento com suas tarefas externas, visto que as concentra nas mãos da diretoria ou das estagiárias de Psicologia. Por isso estamos intervindo no sentido de trabalhar e estimular estratégias de autogestão ou gestôes coletivas e a implicação do próprio grupo com suas ações permanentes.

Alguns resultados do nosso programa de pesquisa-intervenção merecem citação. Dissertações de mestrado foram produzidas no PPGPSI-UFSJ, sendo três delas elaboradas por enfermeiras e duas por psicólogas.

O programa publicou o livro Doce Vida, com receitas dietllights de baixo custo, em parceria com a APD-SJDR e com a Pró-Reitoria de Extensão e Assuntos Comunitários da UFSJ. As receitas foram reunidas com a participação dos associados e familiares, que trouxeram algumas produzidas por eles próprios. Outras foram garimpadas coletivamente em sites de associações de diabéticos. Todo o conteúdo do livro foi discutido em reuniōes da Associação. As receitas são experimentadas e avaliadas em comemorações de aniversários dos associados e, atualmente, em atividades nas unidades de saúde com apoio do Núcleo de Apoio à Saúde da Família (NASF) do Município. Anualmente a APD e o Doce Vida promovem um evento de informação e prevenção em diabetes, aproximadamente em 14 de novembro, celebrado mundialmente, pela Organização Mundial de Saúde, como o Dia Mundial de Combate à Diabetes. Os associados e familiares participam ativamente da organização e realização do evento, em parceria com a Secretaria Municipal de Saúde e a Pró-Reitoria de Extensão e Assuntos Comunitários da UFSJ.

Algumas parcerias com serviços e, ou, políticas públicas foram/vêm sendo estabelecidas e, ou, fortalecidas pelo Lapip e alguns de seus projetos permanentes, como a sala de atividades físicas, a lan house e a brinquedoteca. A lan house e a brinquedoteca desenvolvem atividades diversas em torno da ludicidade e voltadas para públicos de todas as faixas etárias, incluindo idosos moradores no Albergue Santo Antônio, ILPI vizinha ao Campus Dom Bosco da UFSJ e crianças abrigadas nas casas-lares de São João del-Rei e Região das Vertentes. Além disso, são oferecidos treinamentos e cursos de curta duração para professores e técnicos de escolas e outras instituições públicas da região que atendem públicos semelhantes. A sala de atividades físicas do laboratório, única em todo o Brasil, conta com equipamentos para musculação e treinamento funcional adaptados para atendimento de públicos especiais, como idosos, deficientes, diabéticos e adultos com hipertensão, recrutados por meio de contato com unidades básicas de saúde do Município e com outros projetos de extensão da UFSJ. 
Nesse espaço, é oferecido outro programa de extensão em interface com a pesquisa que merece ser mencionado e vem sendo desenvolvido pelo Lapip, em parceria com o Núcleo de Pesquisa em Acessibilidade, Diversidade e Trabalho (NACE) e com o Grupo de Estudos em Atividade Física e Saúde (GEAFES), originário do Departamento de Educação Física da UFSJ. Trata-se do "Promoção de saúde e suas interfaces físicas e psicológicas: programa de intervenção e pesquisa com idosos, pessoas com deficiência, adultos com diabetes e hipertensos". Seus objetivos são: concepção e implantação um programa de promoção de saúde física e psicológica, centrado no aumento da autonomia funcional e melhoria das condiçôes afetivo-emocionais (psicológicas) dos participantes da proposta; avaliação longitudinal dos impactos do programa na autonomia e na melhoria da qualidade de vida dos participantes da proposta; criação de protocolos de intervenção e avaliação física e afetivo-emocional para cada grupo; promoção, reflexão e construção coletiva do conhecimento acerca dos hábitos alimentares adequados aos diabéticos, assim como mudanças no comportamento alimentar. Aqui trabalhamos com referenciais de grupos operativos, oficinas de grupo e processo grupal de Pichón-Rivière (1988) e Afonso (2006); análise da resistência à mudança de hábitos alimentares; construção e, ou, produção coletiva de novos hábitos e formas de lidar com a vida cotidiana; novos corpos e novas formas de pensar sobre a atividade física e a partir da realização cotidiana dela; novos modos de ser grupos e, ou, novas configurações vinculares; comunidades afetivas e, ou, comunhões de afeto; produção coletiva de projetos de vida e de inclusão psicossocial; menor presença de tabus surgidos a partir de um primeiro contato com um profissional da saúde após o diagnóstico da diabetes, no caso do Doce Vida, os membros do grupo relacionam-se entre si para além da simples vinculação técnica com a tarefa a ser realizada, o que favorece a adesão aos tratamentos e, consequentemente, melhorias na qualidade de vida; construção e ampliação de processos de solidariedade entre os participantes dos vários grupos atendidos, já que o trabalho é realizado com grupos compostos por todos os tipos de públicos atendidos. Mais autonomia e melhorias na qualidade de vida e saúde são resultados relatados por todos os participantes.

Tudo isso tem nos feito pensar muito sobre nossas relações e articulações com as políticas públicas de saúde, educação, assistência social, cultura, meio ambiente e desenvolvimento social, tanto no âmbito do município quanto no de políticas estaduais e federais. Perguntamo-nos cotidianamente sobre nossas relações e funções como técnicos do serviço público ou como parceiros de técnicos que desenvolvem essas ações. O tempo de duração das políticas públicas geralmente caminha em descompasso com o tempo de produção de mudanças 
por nossas investigações/intervenções. Nosso tempo é o tempo de Kairós e nos cobram o tempo de Kronos!

Temos colocado para nós mesmos alguns desafios cotidianos que estão se transformando em princípios permanentes de ação e perspectivas permanentes de formação dos nossos alunos, tais como:

a) pensar em e, ou, produzir estratégias de atenção psicossocial como perspectiva terapêutica/perspectiva de cuidado que deve se aplicar a todos os contextos, todos os públicos e campos de nossa atuação;

b) criar para nós mesmos, para nossos alunos e para nosso público estratégias permanentes de provocação, produção, busca e luta pela efetivação de uma cidadania emancipatória e pela possibilidade de produção permanente de subjetividades cidadãs em nossa sociedade. Queremos ser sujeitos dos nossos próprios modos de ser e queremos que nossos objetos/ sujeitos de pesquisa/intervenção também o sejam.

Como se pode ter tempo para ser, no mundo atual, mundo da pressa, da correria da tecnologia acelerada? Como buscar, cada vez mais, o desenvolvimento de políticas públicas de governo e não somente de gestão? Os gestores, de maneira geral, buscam, cada vez mais, políticas públicas que durem o tempo de sua gestão. Não se preocupam muito com políticas de Estado, com políticas públicas que durem mais tempo do que o tempo de duração de seus mandatos. Continuamos presenciando a luta de Kronos contra Kairós:

O tempo de Kronos em oposição ao tempo de Kairós, ou seja, as grandes dificuldades de articulação do tempo de efetivação das políticas públicas com o tempo de efetivação das mudanças de comportamento das comunidades em relação aos problemas de saúde, educação e desenvolvimento social. Kronos é o deus do tempo cronológico, o tempo do relógio, enquanto Kairós é o deus do tempo da reflexão, da filosofia, do pensar (Vieira-Silva, 2015, p. 320).

Trabalhando cotidianamente como grupos, já sabemos que mudanças de comportamentos, de concepções sobre saúde, educação, desenvolvimento social não ocorrem no tempo de Kronos, mas sim no tempo de Kairós. Vimos e vemos isso acontecer no trabalho com os diabéticos na APD-SJDR. Mudança de comportamentos, processos de reeducação nutricional são de mudança lenta. Concepçôes mais críticas sobre direitos humanos, sobre a convivência com diversidades de toda ordem, sobre processos de inclusão psicossocial, quando o sujeito se sente efetivamente incluído, fazendo parte, sendo efetivamente sujeito de seu modo de ser, são processos, são conquistas de médio e longo prazos, não 
são questôes que se resolvem por decretos, por vontades absolutas de alguns iluminados. $\mathrm{O}$ envolvimento e a demanda, cada vez maiores, de programas públicos de atenção e prevenção aos diabéticos e seus familiares é um exemplo que vem da Associação dos Portadores de Diabetes de São João del-Rei. Processos educativos, no sentido "paulofreireano", bem como processos grupais, no sentido "laneano", são provocaçôes e processos dialógicos, lentos por natureza, para que possam ser mais efetivos. Práticas grupais nas perspectivas trabalhadas aqui são transformadoras por natureza, mas são da ordem de Kairós. Demandam paciência pedagógica e compromissos de curto, médio e longo prazos com a transformação social. 


\section{REFERÊNCIAS}

Afonso, M. L. M. (2006). Oficinas em dinâmica de grupo: um método de intervenção psicossocial. São Paulo: Casa do Psicólogo.

Brasil. (1993). Ministério da Saúde. Manual de diabetes. Brasília: Ministério da Saúde.

Ciampa, A. C. (1987). A estória do Severino e a história da Severina. São Paulo: Brasiliense.

Galo, P. P. V. (1998). "Coalhadas" e "Rapaduras": história social da música em São João del-Rei no século XIX. (Monografia de Especialização), Curso de PósGraduação em História de Minas do Século XIX, Fundação de Ensino Superior de São João del-Rei, São João del-Rei.

Heller, A. (1985). Teoria de los sentimientos. Barcelona: Fontamara.

Lane, S. T. M. (1984). O processo grupal. In S. T. M. Lane \& W. Codo (Org.), Psicologia Social: o homem em movimento. (pp. 78-98). São Paulo: Brasiliene.

Lane, S. T. M. (1996). Histórico e fundamentos da Psicologia comunitária no Brasil. In R. H. F. Campos, Psicologia Social Comunitária: da solidariedade à autonomia. (pp. 17-34). Petrópolis: Vozes.

Machado, M. N. M. (2004). Práticas psicossociais: pesquisando e intervindo. Belo Horizonte: Edições do Campo Social.

Maheirie, K. (2003). Processo de criação no fazer musical: uma objetivação da subjetividade, a partir dos trabalhos de Sartre e Vygotsky. Psicologia em Estudo, $8(2), 147-153$.

Martín-Baró, I. (1989). Sistema, grupo y poder. San Salvador: UCA.

Pagés, M. (1976). A vida afetiva dos grupos: esboço de uma teoria das relaçôes humanas. Petrópolis. Vozes.

Pichón-Riviére, E. (1982). Teoria do vínculo. Rio de Janeiro: Zahar.

Pichon-Rivière, E. (1988). O processo grupal. São Paulo: Martins Fontes.

Suplici, S. E. R. (2001). Ludoterapia no processo educativo do cliente diabético. Belo Horizonte: Campo Social. 
Thiollent, M. (1988). Metodologia da pesquisa-ação. (4a ed.). São Paulo: Cortez.

Vieira-Silva, M. (2000). Processo grupal, afetividade, identidade e poder em trabalhos comunitários: paradoxos e articulaçôes. (Tese de Doutorado), Pontifícia Universidade Católica de São Paulo, São Paulo.

Vieira-Silva, M. (2003). As implicações da afetividade e da identidade grupais nas estratégias de construção da cidadania. In A. M. C. Guerra, L. Kind, L. Afonso, M. A. M. Prado (Org.), Psicologia social e direitos humanos. (pp. 201208). Belo Horizonte: Campo Social.

Vieira-Silva, M. (2008). Práticas em Psicologia social comunitária: questionamentos e articulações com a extensão universitária em Minas Gerais. In M. Dimenstein (Org.), Psicologia social comunitária: aportes teóricos e metodológicos. (pp. 87-101). Natal: Editora da UFRN.

Vieira-Silva, M. (2015). Práticas em psicologia comunitária e processos de mobilização social: provocações para um debate. Pesquisas e Práticas Psicossociais, $10,310-323$.

Vieira-Silva, M., Amaral, M. S., \& Grandi, A. (2002, dezembro). Afetividade, identidade e poder em grupos comunitários: características e articulaçōes com o desenvolvimento do processo grupal. Psicologia em Revista, 8(12), 125-129.

Vieira-Silva, M., Assunção, R. V., Moreira, H. C. P., \& Maria, L. S. (2007). Processo grupal e identidade no desenvolvimento de um programa de Psicologia e saúde pública. In Anais do 14 Encontro Nacional da Abrapso, Rio de Janeiro. São Paulo: Abrapso.

Vigotski, L. S. (1999). Psicologia da arte. São Paulo: Martins Fontes. 